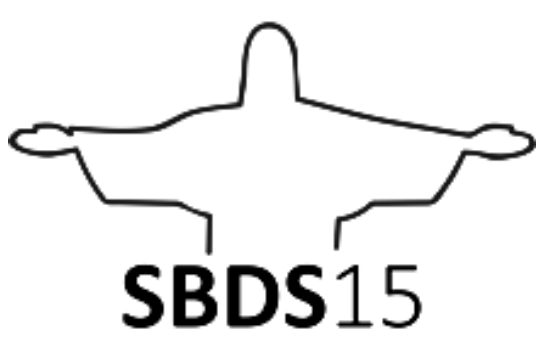

5 SIMPÓSIO DE DESIGN SUSTENTAVELL

\title{
O DESIGNER COMO AGENTE DE TRANSFORMAÇÃO SUSTENTÁVEL NA PRODUÇÃO DE ARTIGOS DE MODA
}

\author{
Cruz, Bárbara de Oliveira \\ barbaradeoliveiraecruz@gmail.com \\ Couto, Rita Maria \\ ricouto@puc-rio.br \\ Portas, Roberta \\ robertaportas@me.com
}

\begin{abstract}
Resumo Um duplo deslocamento - descentralização dos indivíduos tanto de seu lugar no mundo social e cultural quanto de si mesmos - constitui uma "crise de identidade" para o indivíduo, esse será o ponto de partida do artigo. Essa "crise de identidade" é apenas uma das consequências do processo de globalização vivenciado pela humanidade desde o fim do século passado. Outra consequência é a nova divisão global do trabalho gerada pelas novas formas de organização e de produção econômica. O homem moderno perde, primeiramente, sua referência maior de existência: a nação. Depois, suas mentes perdem a capacidade de mapear a enorme rede global de comunicação descentrada. A partir dessas premissas, é possível analisar as causas da crise do trabalho tradicional, bem como tentar buscar soluções para tal ambos os pontos se constituindo no foco do presente artigo. Utilizaremos a produção dos artigos de moda para visualizarmos que o processo de alienação humana começa com a divisão do trabalho na revolução industrial e passa por uma hiper aceleração através da globalização e do capitalismo multinacional, bem como o papel dos designers como agentes de transformação.
\end{abstract}


Palavras chave: Sustentabilidade, Moda, Design

\begin{abstract}
Double displacement - decentralization of individuals both in terms of the individual's place in the social and cultural world as well as of the self - results in an "identity crisis" for the individual, this shall be the starting point for the paper. This "identity crises" is only one amongst many of the consequences of the process of globalization experienced by human kind since the end of the last century. Another of these consequences is the new global division of labor and economic production. Modern man loses, first, its most important of reference: the nation. Then, his/her mind loses the ability to map the enormous decentralized communications network. It is possible to analyze the causes of the crises facing traditional labor, as well as to try and find solutions for it - both points are the focus of this paper. We shall make use of the production of fashion articles so as to visualize that the human alienation process starts at the division of labor in the industrial revolution and goes through hyper acceleration through globalization and multinational capitalism, as well as the roll of designers as agents of transformation.
\end{abstract}

Keywords: Sustainability, Fashion, Design

\title{
INTRODUÇÃO
}

As velhas identidades, que por tanto tempo estabilizaram o mundo social, estão em declínio, fazendo surgir novas identidades e fragmentando o indivíduo moderno, até então visto como um sujeito unificado. O argumento, de Stuart Hall (2004), é o ponto de partida para a compreensão da produção contemporânea de artigos de moda bem como do papel transformador do designer. A chamada "crise de identidade" é segundo Hall, parte de um processo mais amplo de mudança, que está deslocando as estruturas e processos centrais das sociedades modernas e abalando os quadros de referência que davam aos indivíduos uma ancoragem estável no mundo social.

Ao discutir os rumos que a identidade cultural tomará a partir desse período, Hall questiona se essa identidade cultural entrará ou não em crise, pois seu deslocamento e fragmentação já são fatos constatados. As transformações pelas quais as sociedades modernas estão passando desde o final do século XX vêm fragmentando 
as paisagens culturais de classe, gênero, sexualidade, etnia, raça e nacionalidade, que no passado nos forneciam sólidas localizações como indivíduos sociais. E o fenômeno está, assim, mudando nossas identidades pessoais, abalando a ideia que temos de nós próprios como sujeitos integrados. Esse duplo deslocamento - descentralização dos indivíduos tanto de seu lugar no mundo social e cultural quanto de si mesmos constitui uma "crise de identidade" para esse indivíduo (HALL, 2004, p.9).

A "crise de identidade" é uma das consequências do processo de globalização vivenciado pela humanidade desde o fim do século passado. Segundo explicação de Giddens, a base da crise está nos processos atuantes em escala global que atravessam fronteiras nacionais, integrando e conectando comunidades e organizações em novas combinações de espaço e tempo, tornando o mundo, em realidade e em experiência, mais interconectado. A globalização implica um movimento de distanciamento da ideia sociológica clássica da sociedade como um sistema bem delimitado e sua substituição por uma perspectiva que se concentra na forma como a vida social está ordenada ao longo do tempo e do espaço (GIDDENS, 1990 apud HALL, 2004).

A partir dessas transformações, começamos a perceber que, diferentemente do que os sociólogos pensavam, a sociedade não é um todo unificado que se forma e que se modifica a partir de si mesma, ela está constantemente sendo influenciada e sofrendo modificações de origem externa.

Parece clara e pertinente a afirmação de Hall sobre a descentralização dos indivíduos e sua crise de identidade, bem como o efeito desse processo que abre a possibilidade de produção de novos sujeitos.

O presente artigo que tem como objetivo mostrar algumas implicações da produção de artigos de moda no âmbito do processo de globalização, bem como o papel dos designers como agentes de transformação, tem nas ideias de Stuart Hall e Frederic Jameson uma inspiração.

\section{SOBRE O PAPEL DO DESIGN SUSTENTÁVEL}


Para Hall, devemos ter em mente a forma pela qual as culturas nacionais contribuem para costurar as diferenças numa única identidade. As identidades nacionais podem estar em declínio, mas novas identidades híbridas - estão tomando seu lugar. É preciso pensar numa nova articulação entre o global e o local. O local não deve ser confundido com velhas identidades, ele deve atuar no interior da lógica da globalização. Parece improvável que a globalização vá destruir identidades nacionais. A fusão entre diferentes traduções culturais são uma poderosa fonte criativa, produzindo novas formas de cultura, mais apropriadas à modernidade tardia que às velhas e contestadas identidades do passado (HALL, 2004, p.91).

Jameson (1997) também se debruçou sobre a questão definindo sua obra e a de outros autores como teoria do pós-modernismo. Ele esclarece que não pretende dar soluções, mas apenas investigar e exemplificar o que chama de lógica cultural do capitalismo tardio, defendendo a riqueza literária do período diante da rasa produção estética. Enquanto Hall usa o termo modernidade tardia, Jameson prefere pósmodernismo e capitalismo tardio, terceiro estágio do capitalismo ou capitalismo multinacional. A partir daí, já se pode perceber que a exposição de Jameson abrange não só a esfera cultural, mas também as esferas política e econômica do período.

“O pós-modernismo não é a dominante cultural de uma ordem social totalmente nova, mas é apenas reflexo e aspecto concomitante de mais uma modificação sistêmica do próprio capitalismo" (JAMESON, 1997, p.61). Visualizando o aspecto político e econômico da época, fica clara a localização da cultura, que é tratada como mercadoria e nos leva a um diagnóstico mais preciso do período onde há uma supervalorização do consumo. O consumismo passa a ser, dessa forma, mais importante que o valor cultural. E a produção estética começa a ser integrada à produção das mercadorias em geral.

No âmbito dessa esfera política e econômica, outro ponto de grande importância é a nova divisão global do trabalho gerada pelas modernas formas de organização e de produção econômica. "Essa divisão do trabalho vem acompanhada da nova divisão de novos mecanismos de transações bancárias internacionais, da fuga da produção para áreas do terceiro mundo, ao lado das consequências sociais mais conhecidas, incluindo a crise do trabalho tradicional" (JAMESON, 1997, p.22). Que parcela do mundo cada país está tomando nessa globalização? Quem rege essa divisão? A reposta para essas perguntas está no próprio sistema capitalista. Difundiu- 
se a crença no inicio de todo esse processo, que as mudanças poderiam causar uma maior inclusão social, gerada pela globalização de informações e oportunidades. Hoje, no entanto, percebe-se que globalização e inclusão não andam necessariamente juntas. Começamos, então, a tentar entender a esfera social dessa problemática.

A fragmentação, o deslocamento e essa nova forma de organização de produção econômica geram, segundo Hall (2004), uma alienação do indivíduo. O homem moderno perde, primeiramente, sua referência maior de existência: a nação. Depois, suas mentes perdem a capacidade de mapear a enorme rede global de comunicação descentrada (Jameson 1997). A partir dessas premissas, é possível analisar as causas da crise do trabalho tradicional, bem como tentar buscar soluções para tal - ambos os pontos se constituindo no foco do presente artigo.

Como explica Thackara (2008) a internet, maior responsável pela aceleração do processo de globalização possibilitou a formação das cadeias produtivas globais. Essa globalização e o "capitalismo multinacional" (Jameson 1997) trouxeram uma hiper aceleração da alienação humana. Hoje não existe apenas uma divisão do trabalho dentro de um espaço físico denominado fábrica. Agora essa divisão do trabalho é mundial. Cada fábrica em um lugar do mundo é responsável por uma etapa da produção. Outro desafio que a globalização traz ainda para as comunidades atuais é viver com o resultado da comercialização de seus produtos dentro do mercado consumidor globalizado.

O fast fashion, um fenômeno recorrente no mercado de moda, exemplifica de forma clara os aspectos citados anteriormente, uma vez que representa a consolidação de um novo sistema produtivo gerado pelas mudanças nas práticas culturais, políticas e econômicas no pós-modernismo. Segundo Contino, esse processo tem origem no sistema produtivo e não no consumo, como pensam alguns. O consumo já seria um efeito da própria produção (CONTINO, 2015, P.10).

O fast fashion ou "moda rápida" tem como finalidade acelerar o giro do capital através do aumento do consumo. Muitas vezes são utilizados conceitos de democratização da moda como forma de defender esse fenômeno ou amenizar seus efeitos: vamos vender um produto com uma marca de luxo, assinada por um estilista 
famoso, por um preço accessível a todos os públicos. E como isso é possível? Espremendo os custos para que as margens de lucro continuem altas. Desvalorizando, assim, a produção e todas as pessoas que estão envolvidas nela, ou pelo menos em sua base. Como pensar em democratização olhando por esse ângulo?

É preciso ressaltar aqui que essa questão na indústria de confeç̧ão de artigos de modas não surgiu com o fast fashion. A exploração da força de trabalho e a informalidade do setor assombram o mercado há mais de um século. Quando comparamos a confecção de roupas a outras indústrias, até mesmo dentro da própria área de moda, onde temos a tecelagem e a estamparia têxtil, percebemos que houve uma pequena evolução técnica dos processos. A confecção de peças de vestuário continua a ser uma atividade intensiva em trabalho. E essa situação é, desde a revolução industrial, movida por uma conflituosa relação entre os agentes. Numa visão marxista, estamos falando da exploração de trabalho, característica intrínseca ao sistema capitalista. Nesse segmento produtivo, podemos visualizar claramente o que foi mencionado antes: que o processo de alienação humana começa com a divisão do trabalho na revolução industrial e passa por uma hiper aceleração através da globalização e do capitalismo multinacional.

Aquilo a que Jameson (1997) nos introduz como a problemática da crise do trabalho tradicional através da nova divisão global do trabalho, Contino (2015) nos demonstra com a precarização da força de trabalho na produção de artigos de moda, além da desterritorialização da produção. Eis o que parece ser a consequência mais grave de toda esta situação. E existem ainda outros problemas que talvez não sejam tão evidentes, mas que merecem ser mencionados.

O cenário causado pela globalização e pelo capitalismo tardio parece terrível, pelo menos com o panorama abordado na área de moda. Na esfera cultural falamos sobre crise de uma identidade cultural gerada por uma massificação da cultura, e a localização da cultura como mercadoria onde seu valor financeiro (no mercado) vem priorizado em relação a o seu valor simbólico. E na esfera social falamos de desigualdade social, divisão do trabalho gerando a alienação do homem em relação 
aos processos produtivos, precarização da força de trabalho e crise do trabalho tradicional.

Tentando recortar ainda mais essa situação, com o foco no Brasil, propõe-se um deslocamento na pirâmide social da produção para visualizar os responsáveis pelas criações: os designers de moda. Como e onde estão os designers de moda brasileiros? Abandonaram suas profissões e foram tentar novas opções e novas carreiras? Renderam-se a esse sistema? Viraram blogueiros frenéticos divulgando tendências? A pergunta que ecoa é: o que vai acontecer a essa profissão nos próximos anos se não houver mudanças significativas? A carreira vai se desligar da produção industrial, deixando de ser uma vertente do Design e vai migrar para Belas Artes? Procurará um caminho mais comercial e financeiramente viável através do consumo audiovisual e da propaganda?

Impossível não pensarmos em crise de identidade cultural nesse cenário. Afinal sabemos que os designers de moda junto com designers gráficos, designers de produto, arquitetos e outros profissionais são os responsáveis pela criação da cultura material local.

Voltando às conclusões de Hall (2004), lembramos que as culturas tradicionais serão gradualmente transformadas em novas identidades culturais, agora híbridas. Ele nos mostra também que essa descentralização do sujeito a partir do período do capitalismo tardio causou a erosão da identidade mestra da classe e a emergência de novas identidades, pertencente à nova base política definida pelos movimentos sociais: o feminismo, as lutas negras, os movimentos ecológicos (HALL, 2004, p.21). Somente através desse novo sujeito e dessas novas formas de organização da sociedade civil será possível atendermos à convocação de Jameson:

Uma estética do mapeamento cognitivo - uma cultura política e pedagógica que busque dotar o sujeito individual de um sentido mais aguçado de seu lugar no sistema global - terá, necessariamente, que levar em conta essa dialética representacional exatamente complexa e inventar formas radicalmente novas para Ihe fazer justiça. Esta não é, então, uma convocação para a volta a um tipo mais antigo de aparelhagem, a um espaço nacional mais antigo e transparente, ou a qualquer enclave de uma perspectiva mimética mais tradicional e tranquilizadora: a nova arte política (se ela for de fato possível) terá que se ater à verdade do pós-modernismo, isto é, a seu objeto fundamental - o espaço 
mundial do capital multinacional -, ao mesmo tempo que terá que realizar a façanha de chegar a uma nova modalidade, que ainda não somos capazes de imaginar, de representá-lo, de tal modo que nós possamos começar novamente a entender nosso posicionamento como sujeitos individuais coletivos e recuperar nossa capacidade de agir e lutar, que está, hoje, neutralizada pela nossa confusão espacial e social. A forma política do pósmodernismo se houver uma, terá uma vocação a invenção e a projeção do mapeamento cognitivo global, em uma escala social espacial (JAMESON, 1997, p.79).

Sob essa perspectiva, o autor sugere novas organizações capazes de promover mudanças. Além de se autodenominar um teórico do período que não vai propor soluções, ele afirma que surgirão pessoas pós-modernas capazes de dar respostas e não apenas teorias.

Ainda que lentamente, já começamos a perceber tentativas de mudanças a partir de ideias de estudiosos que nos apontam caminhos viáveis para a produção de artigos de moda e um futuro para os designers e moda. É o caso do pesquisador e designer Ezio Manzini, quando propõe tentativas através de práticas sustentáveis. 0 termo sustentabilidade surgiu como resposta a essa sociedade de consumo e suas práticas irresponsáveis de produção. Inicialmente, era usado apenas para causas ecológicas de defesa do meio ambiente, mas se expandiu e hoje atinge outras áreas, como a social. O desenvolvimento social sustentável é, portanto, a capacidade de sustentação gerada pela sociedade em seu próprio benefício tendo como foco principal o bem estar social.

Mas o que é o bem estar social? Ironicamente, a ideia que temos hoje no Ocidente se fortaleceu com a Revolução Industrial e está diretamente ligada ao consumo insustentável dos recursos ambientais. Consumo de produtos a preços acessíveis que podem reduzir o esforço, aumentar o tempo livre, aumentar as oportunidades de escolha, fazendo o sujeito acreditar em uma libertação individual. Como, então, desassociar a sensação de bem estar à aquisição de novos produtos por uma sociedade que já vive assim há mais de um século? Começam a emergir novas ideias para esse desafio. A sensação de bem estar começa a se dissociar do consumismo exacerbado de produtos, quando o indivíduo percebe que esse tipo de satisfação pessoal não pode ser mais importante que o cuidado com todos que o 
cercam. Precisamos lembrar que a principal função do designer é melhorar a qualidade do mundo e não apenas a estética dos produtos.

Manzini afirma que a sustentabilidade deveria ser a meta-objetivo de todas as pesquisas em design, mas como esse objetivo ainda não foi atingido, continuamos a usar a expressão "design para a sustentabilidade". Em síntese, o design para a sustentabilidade é o design estratégico capaz de colocar em ato descontinuidades locais promissoras, contribuindo para efetivas mudanças sistêmicas. Para isso, devemos experimentar novas possibilidades e romper com esses processos dominantes de produção e consumo (MANZINI, 2008, p.15).

Manzini vê, através do design estratégico, o designer como um agente responsável pelas mudanças. $\mathrm{O}$ designer deve parar de desperdiçar sua criatividade e habilidade metodológica em projetos insustentáveis e individualistas e utilizá-las de forma benevolente e sustentável. Por essas características, o designer é o profissional mais indicado a transformar comunidades comuns em comunidades criativas e tornálas autossustentáveis. Estas serão sociedades independentes dentro dos princípios da sustentabilidade socioambiental, que resultem em geração de renda ao mesmo tempo em que perpetuam seu saber tradicional, seu modo de vida, permanecendo em seus territórios, defendendo o seu ambiente e respeitando sua identidade e suas tradições.

Podemos dizer, enfim, que as comunidades criativas aplicam sua criatividade para quebrar os modelos dominantes de pensar e fazer e, com isso, conscientemente ou não, geram as descontinuidades locais (MANZINI, 2008, p.65).

\section{CONCLUSÃO}

Através dessa nova estrutura de comunidades criativas proposta por Manzini, onde existe essa troca entre os saberes dos designers e os dos integrantes do grupo, seguindo a trilha da sustentabilidade, será possível achar soluções para alguns problemas abordados por nós. Através da capacidade de se organizar coletivamente o indivíduo será capaz de agir e lutar por uma causa que favorecerá a todos que o cercam.

Mas como e porque o designer é o profissional mais indicado? De que forma o designer pode influenciar positivamente na formação das comunidades criativas e na capacitação de seus integrantes? O designer pode oferecer novas soluções a 
problemas e propor novos cenários como tema em processos de discussão social. As habilidades do designer e seu modo de agir criativamente são características fundamentais para o homem contemporâneo. Através dessas habilidades e dessa criatividade o homem poderá achar alternativas inovadoras e colaborativas. "O designer será capaz de projetar uma nova geração de artefatos que sejam ao mesmo tempo apreciados pelos potenciais usuários e capazes de regenerar a qualidade do contexto onde se encontram (MANZINI, 2008, p.57)".

Jeremy Rifkin fez, em 2005, uma análise sobre as transformações que estão acontecendo no mercado de trabalho neste século. Ele previu: "por volta do ano 2020, haverá uma eliminação virtual do trabalhador da indústria no mundo inteiro. Menos de $2 \%$ da força de trabalho deste planeta estará na indústria (RIFKIN, 2005, p.14)". Ele exemplifica ainda que a indústria de confecção de artigos de moda, por ser intensiva em mão de obra, é responsável pelo crescimento de países em vias de desenvolvimento da Ásia e da América do Sul e que talvez em apenas cinco anos o processo de costurar uma peça será automatizado. E questiona o que vai acontecer a esses países depois que os Estados Unidos automatizarem os processos de costura de uma peça de roupa. Mas estamos em 2015 e será que isso realmente aconteceu? Discordamos do autor e acreditamos que o setor continuará a ser intensivo em mão de obra por muitos e muitos anos. A pergunta que nos interessa é: quais as condições de trabalho oferecidas a essas pessoas? Rifkin ainda deixa duas perguntas para reflexão: que fazer com milhões de pessoas, em cada país que, dia a dia, são mais (mais ou completamente) desnecessárias numa economia cada vez mais global e automatizada? Como começar um debate sobre o meio de dividir melhor o enorme potencial de produtividade dessa tecnologia, de forma a beneficiar não somente uma pequena elite, mas a sociedade inteira?

Uma pesquisa realizada na cidade de São Paulo pelo Núcleo de Ação e Pesquisa em economia e Solidariedade - NAPES -, com o apoio do Fundo de Miniprojetos da Fundação Unitrabalho e da Central Única os Trabalhadores CUT - identificou 41 empreendimentos comunitários, com 13 pessoas em média em cada grupo. Quanto à atividade econômica são: $37 \%$ oficinas de costura e de trabalho com tecido, 19\% artesanato, 15\% alimentação e $10 \%$ coleta seletiva de lixo (MELO NETO E FRÓES, p.73, 74). 
Utilizo esses dados para fortalecer a nossa opinião de que a manufatura de peças de vestuário é um setor propício à formação de empreendimentos comunitários utilizando costura e trabalhos artesanais. Eis aqui, então, o traçado de um possível futuro para os designers de moda brasileiros. Por que abandonarem seus talentos e suas profissões? Por que não atuarem junto a grupos cooperativos facilitando dessa forma o processo de inclusão social?

A questão social sempre esteve presente desde o início da formação do design mostrando ao designer que o caminho deve ser regido pela lógica do usuário ao invés da lógica da produção. Esse é o conceito clássico do design social que hoje assume um papel ainda mais importante dentro de um contexto político e econômico: a inclusão social. Configurando então um novo design social, o designer pode ser o agente que promove essa inclusão social valorizando o papel de trabalhadores na produção e na concepção de artigos com forte valor cultural. Segundo Couto (1992), o design é basicamente um processo de interação social e como tal, não é socialmente neutro, sendo influenciado por interesses dos participantes do seu processo.

Couto (1992) acredita ainda que o designer não projeta sozinho, mas ajuda a distribuir conhecimento para que a população possa produzir, ela mesma, as coisas de que necessita. Essa estrutura de trabalho faz parte de uma visão multidisciplinar e colaborativa, na qual a autoria não é apenas do designer, mas sim, de todos os envolvidos no processo de produção, sendo um exemplo claro de processo coletivo colaborativo onde não há uma liderança, tratando-se portanto de uma parceria ou codesign.

Como sugeriu Hall (2004) é preciso pensar numa nova articulação entre o global e o local. O local não deve ser confundido com velhas identidades, ele deve atuar no interior da lógica da globalização. Essa nova articulação segundo Manzini (2008) será iniciada através das descontinuidades locais se configurando na mudança de comportamento de uma comunidade, que aparecem a partir de processos organizacionais e colaborativos "de baixo para cima", para resolver problemas e criar novas oportunidades. Thakara (2008) defende ainda que o designer pode se favorecer com essa articulação utilizando a diferença cultural, de local e de tempo de forma positiva e não como obstáculo. "Quando pessoas na periferia, ideias e organizações 
periféricas são combinadas, isso costuma resultar em algo interessante e valioso" (THAKARA, 2008, p.267).

Mas como encorajar a produção local sem ser esmagado pelo poder dos mecanismos de comércio global? Fica difícil pensar nessa transição em uma sociedade que hoje vive imersa no crescimento da produção e na valorização do consumo como condições normais de sobrevivência. Mas esse é apenas o ponto de partida de uma estratégia rumo à sustentabilidade. O que precisa acontecer é uma mudança na base do complexo sistema (social, econômico e político) da sociedade industrial. Não podemos prever se, quando e como isso acontecerá. Infelizmente o sistema sóciopolítico-econômico de nossa sociedade ainda é regido pelo mercado e pelos modelos de desenvolvimento de base econômica e continuam a caminhar no sentido oposto da sustentabilidade.

Mas o ponto mais importante a ser considerado é que essas comunidades criativas irão reorientar-se para um novo estilo de vida sustentável, um número cada vez maior de pessoas potencializando o caminho para essa mudança de paradigma sugerida: substituição do modelo atual de desenvolvimento econômico para o social.

"Para haver uma descontinuidade sistêmica em escala macro é preciso que ela seja precedida de muitas descontinuidades locais, isto é, mudanças radicais em escala local" (MANZINI, 2008, p.19).

\section{REFERÊNCIAS}

CONTINO, Joana Martins. Fastfashion: apontamentos sobre as transformações da moda na condição pós-moderna.2015 Disserteção(mestrado) - PUC-Rio,Curso de Pósgraduação em Design.

COUTO, Rita Maria de Souza. Reflexões sobre Design Social, por Rita Maria de Souza Couto, PUC Rio, 1992. 
HALL, Stuart. A identidade cultural na pós-modernidade. Rio de Janeiro: Editora DP\&A, 2004.

JAMESON, Frederic. Pós-modernismo - a lógica cultural do capitalismo tardio. São Paulo: Editora Ática, 1997.

MANZINI, Ezio. Design para a inovação social e sustentabilidade - Comunidades criativas, organizações colaborativas e novas redes projetuais. Rio de Janeiro: Editora e-papers, 2008.

MELO NETO, Francisco Paulo de; FROES, César. Empreendedorismo social, a transição para a sociedade sustentável. Rio de Janeiro: Qualitymark editora, 2002. 